\title{
"Passing Out is a Serious Thing": Patient Expectations for Syncope Evaluation and Management
}

\author{
Jessica Miller Clouser (D)' \\ Matthew Sirrine' \\ Colleen A McMullen ${ }^{2,3}$ \\ Amy M Cowley' \\ Susan S Smyth ${ }^{2-4}$ \\ Vedant Gupta $\mathbb{1 D}^{2,3}$ \\ Mark V Williams ${ }^{1,5}$ \\ Jing $\operatorname{Li} \mathbb{D}^{1,3}$
}

'Center for Health Services Research, College of Medicine, Lexington, KY, USA;

${ }^{2}$ Gill Heart \& Vascular Institute, UK

HealthCare, Lexington, KY, USA;

${ }^{3}$ Department of Cardiovascular Medicine,

College of Medicine, Lexington, KY, USA;

${ }^{4}$ Lexington Veterans Affairs Health Care

System, College of Medicine, Lexington,

KY, USA; ${ }^{5}$ Division of Hospital Medicine,

UK HealthCare, University of Kentucky,

Lexington, KY, USA
Correspondence: Jing Li

Center for Health Services Research, University of Kentucky, I I 5 Waller Health Care Annex, Rm 304a, Lexington, KY, 40503, USA

Tel + I 8592181038

$\mathrm{Fax}+\mid 859257052$ I

Email jingli.tj@uky.edu
Purpose: Syncope is a complex symptom requiring thoughtful evaluation. The ACC/AHA/ HRS published syncope management guidelines in 2017. Effective guideline implementation hinges on overcoming multilevel barriers, including providers' perceptions that patients prefer aggressive diagnostic testing when presenting to the emergency department (ED) with syncope, which conflicts with the 2017 Guideline on Syncope. To better understand this perceived barrier, we explored patient and family caregiver expectations and preferences when presenting to the ED with syncope.

Patients and Methods: We conducted semi-structured focus groups $(\mathrm{N}=12)$ and in-depth interviews $(\mathrm{N}=19)$ with patients presenting to the ED with syncope as well as with their family caregivers. Interviews were recorded, transcribed verbatim, and analyzed by a team of researchers following a directed content analysis. Results were reviewed and shared iteratively with all team members to confirm mutual understanding and agreement.

Results: Syncope patients and caregivers discussed three main desires when presenting to the ED with syncope: 1) clarity regarding their diagnosis,; 2) context surrounding their care plan and diagnostic approach; and 3) to feel seen, heard and cared about by their health care team.

Conclusion: Clinicians have cited patient preferences for aggressive diagnostic testing as a barrier to adhering to the 2017 Guideline on Syncope, which recommends against routine administration of imaging testing (eg, echocardiograms). Our results suggest that while participants preferred diagnostic testing as a means to achieve clarity and even a feeling of being cared for, other strategies, such as a patient-engaged approach to communication and shared decision-making, may address the spectrum of patient expectations when presenting to the ED with syncope while adhering to guideline recommendations.

Keywords: implementation science, patients, statements and guidelines

\section{Introduction}

Syncope, or fainting, is a common reason that patients seek medical care in the United States. One-half of all Americans are estimated to experience syncope at some point during their lives, with recurrence rates as high as $13.5 \%{ }^{1}$ An estimated $1 \%$ to $3 \%$ of all emergency department (ED) visits - and up to $6 \%$ of all hospital admissions - are due to syncope. ${ }^{1-3}$ The experience of fainting can diminish one's physical and mental health. ${ }^{4-9}$ Recurrent syncope can lower a person's quality of life to a degree that is comparable with chronic lower-back pain and severe rheumatoid arthritis. ${ }^{6}$ Despite advancements in our understanding of particular etiologies of syncope, accurately 
diagnosing patients remains a challenge. Upon arrival to the $\mathrm{ED}, 45 \%$ of syncope patients are not diagnosed as syncopal ${ }^{10}$ due to patients being asymptomatic at the time of presentation. This uncertainty leads to unnecessary testing and inappropriate admissions. ${ }^{11}$ As a result, syncope costs have ballooned in the United States ${ }^{12}$ and Canada ${ }^{13}$ presenting a significant financial and safety burden to patients.

To aid in improving diagnostic accuracy and reducing unnecessary testing and admissions, the American College of Cardiology (ACC), American Heart Association (AHA), and Heart Rhythm Society (HRS) jointly released an updated guideline protocol on the evaluation and management of syncope in 2017, heretofore referred to as the "2017 Guidelines on Syncope". ${ }^{11}$ These guidelines provide recommendations on appropriate procedures employed toward the diagnoses and treatment of syncope by weighing the available evidence of potential benefit versus risk. For example, taking comprehensive patient histories and physical examinations are recommended as routine practice in the evaluation of patients with syncope, while routine cardiac imaging - unless cardiac etiology is suspected - is not recommended. However, a recent statewide survey in Kentucky found a significant gap between current practices and guideline recommendations, ${ }^{14}$ suggesting a need for effective implementation strategies of the 2017 Guidelines on Syncope. Implementing the Guidelines should encourage appropriate use of clinical testing, aid in diagnosis, reduce unnecessary hospital admission, and reduce hospital length of stay. Independent teams have reported successful outcomes by implementing parts of the European Society of Cardiology guidelines at single-center sites in other countries, ${ }^{15,16}$ but less research has focused on efforts in the United States. To be successful, an implementation strategy should be informed by knowledge of the facilitators and barriers experienced by clinicians in their diagnosis and treatment of syncope. Further, by understanding that barriers to guideline implementation can exist at multiple levels (ie organizational, healthcare provider, or patient), identifying the barriers at each level is imperative. ${ }^{17}$

Aiming to develop a multicomponent, multilevel implementation strategy for the 2017 Guidelines on Syncope, we conducted Project MISSION (Developing a multicomponent, Multilevel Implementation Strategy for Syncope OptImalCare thrOugh eNgagement). ${ }^{14}$ This multicomponent study first assessed potential gaps in adherence to guideline implementation by conducting physician surveys and chart reviews of syncope patients. Results showed that according to guideline recommendations, patient histories and physical examinations were underutilized and echocardiograms and neurologic testing were overutilized. ${ }^{14}$ In addition, through surveys and focus groups with clinicians, we found numerous barriers to guideline implementation, including patientfocused barriers. One was the rise in consumerism in health care and the resultant pressure to satisfy patients, who may prefer a more aggressive approach to diagnostic testing than is recommended by the 2017 Guidelines on Syncope. ${ }^{18}$ In addition, communication challenges between patients and providers were cited as a barrier to providers' adhering to guideline-recommended care, especially given the complexity of syncope itself ${ }^{14,18}$

No previous research has explored these perceived patient-level barriers to guideline implementation by interviewing patients to identify their perspectives regarding syncope treatment. Therefore, in this study, we sought to explore the context surrounding perceived patient-level barriers to implementing the 2017 Guidelines on Syncope, develop mitigation strategies, and report patients' suggestions for improved syncope care.

\section{Patients and Methods}

\section{Study Design}

Study Framework

Project MISSION was guided by the Consolidated Framework for Implementation Research (CFIR), which considers constructs at multiple levels (eg, Outer Setting, Inner Setting, Implementation Characteristics) when planning for the successful implementation of an intervention. The present study specifically addresses the "Individual Characteristics" of patient needs, values, and preferences. ${ }^{17}$ See Table 1 for how the present study activities map to CFIR domains and fit within the broader study.

For the patient and family caregiver interviews and focus groups reported here, we employed a directed content analysis, incorporating deductive and inductive approaches to building theory. ${ }^{19}$ This approach allowed us to build upon previous work indicating that clinician adherence to 2017 Guidelines on Syncope may be influenced by patient expectations, while allowing for flexibility in emergent themes from the patient perspective. To examine patients' perspectives during and after the syncopal episode, we conducted patient interviews both in the ED and after discharge. Most in-person interviews $(n=12)$ occurred in the ED prior to discharge,with one held postdischarge. All phone-based interviews $(\mathrm{n}=7)$ and in-person focus groups $(n=12)$ occurred within a few weeks of patient discharge. The data that support the findings of this study are 
Table I Study Activities to Assess Barriers and Facilitators Based on CFIR Constructs

\begin{tabular}{|c|c|c|}
\hline Domain & Construct & Assessment within Project MISSION \\
\hline \multirow[t]{2}{*}{ Inner Setting } & Readiness for Implementation & $\begin{array}{l}\text { Surveys, focus groups and key informant interviews - } \\
\text { clinicians and stakeholders }{ }^{18}\end{array}$ \\
\hline & $\begin{array}{l}\text { Structural characteristics (eg, availability of electronic } \\
\text { information infrastructure) }\end{array}$ & $\begin{array}{l}\text { Focus groups and key informant interviews - clinicians and } \\
\text { stakeholders }{ }^{18}\end{array}$ \\
\hline \multirow[t]{2}{*}{$\begin{array}{l}\text { Individual } \\
\text { Characteristics }\end{array}$} & Patient needs, values, and preferences ${ }^{a}$ & $\begin{array}{l}\text { Individual and focus froup interviews - patients and family } \\
\text { caregivers }\end{array}$ \\
\hline & Provider attitudes to evidence-based practices & Survey of clinicians and stakeholders ${ }^{14,18}$ \\
\hline $\begin{array}{l}\text { Intervention } \\
\text { Characteristics }\end{array}$ & $\begin{array}{l}\text { Strength of evidence, relative advantage, adaptability, and } \\
\text { complexity }\end{array}$ & $\begin{array}{l}\text { Focus groups and key informant interviews - clinicians and } \\
\text { stakeholders }{ }^{18}\end{array}$ \\
\hline
\end{tabular}

Note: ${ }^{\text {a}}$ Focus of the present article.

available on request from the corresponding author. The data are not publicly available due to privacy or ethical restrictions.

\section{Setting}

The present study was set in the University of Kentucky emergency department (ED), a Level I trauma center and academic medical center. In-person focus groups consisted of four sessions with patients and caregivers separately or mixed in private conference rooms within the facility. Individual interviews were conducted at ED patients' bedsides. Given scheduling difficulties, we added individual phone interviews with patients who had recently been discharged after presenting to the ED with syncope.

\section{Participant Selection}

Patients were eligible if they presented to the hospital ED with an admission for and/or primary diagnosis of syncope, ICD code R55. Research staff monitored admission dashboards and approached eligible patients for participation. Family caregivers were eligible if they were at the scene of the patient's syncope episode and/or they were the primary caregiver. Participants were excluded if they were under the age of 18, incarcerated, non-English speaking with no translator present, unresponsive and/or had impaired consent capacity. Once the patient/caregiver provided informed consent, the recruiting staff collected demographic data and conducted the interview onsite or scheduled it for a future date.

\section{Ethics}

All participants provided written, informed consent prior to participating; participants consented to our writing about and sharing combined, anonymous information from the study. Our research was conducted in accordance with the Declaration of Helsinki; the Medical Institutional Review Board at the University of Kentucky (protocol \#45255) approved this study.

\section{Data Collection Interview Guide}

The research team collaboratively developed a semi-structured interview guide; the team included health services researchers, hospitalists, cardiologists, and emergency medicine physicians. Interview questions were based on literature review and study team's experience in implementing evidence-based practices, including CFIR. ${ }^{20}$ Patients and caregivers were asked to elaborate on their experience, perspectives, opinions and attitudes relating to their ED or hospital admission for syncope. Questions for both patient and family caregivers included the broad categories listed in Table 2 with follow-up probes as appropriate.

\section{Interviewers/Moderators}

A team of three faculty researchers moderated the interviews. Faculty moderators included two clinicianresearchers with extensive experience in facilitation and patient-centered outcome research (JL, MVW), and a researcher with extensive experience in qualitative health services research, including among vulnerable populations (HS). Faculty (HS) and research staff (AMC, MOS) conducted phone-based and face-to-face individual interviews. All interviewers were trained in qualitative interview techniques by the faculty researchers, including techniques on how to build rapport with participants and how to effectively probe. 
Table 2 Interview Guide Outline

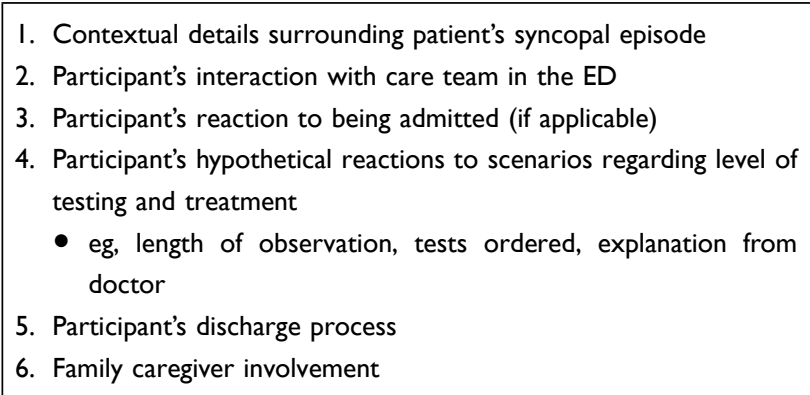

\section{Procedures}

Data were collected from October 2018 to June 2019 through 11 individual interviews conducted prior to discharge in the ED as well as 2 in-person, focus groups with patients and caregivers (one with 5 , one with 7 participants), one patient interview, and 7 phone-based interviews (one included both a patient and caregiver) conducted post-discharge. We initially planned to interview only after discharge. However, based on the iterative content analysis, our team decided to add ED interviews conducted prior to discharge in order to collect data from patients at different time points throughout the episode. Phone interviews were conducted if participants experienced barriers to an in-person interview. Each interview began with an overall explanation of the project's purpose and introductions of all attendees to foster rapport. Focus groups had more than one facilitator to help ensure participation and additional research staff to take notes (AMC, MOS). On average, focus groups lasted approximately 40 minutes (Range: 30-53 minutes); phone and ED interviews lasted approximately 15 minutes.

All focus groups and interviews were audio recorded. Recordings were transcribed verbatim and quality checked by an independent researcher. Transcriptions were entered into NVivo 12 (QSR International, London), a qualitative analysis software, for subsequent analysis. Notes were used to aid in transcription and in the development of themes.

\section{Data Analysis}

Transcriptions were coded using a rigorous team-coding approach. Two independent coders among a team of three (AMC, CDC, MOS) blindly coded one focus group and one individual interview with a pre-set codebook developed by the research team. Codebook development was informed by study members' clinical and implementation science expertise, the concept of shared decision-making integration into clinical practice guidelines, ${ }^{21}$ research regarding patient and family caregiver desires during hospital discharge/transitional care processes, ${ }^{22}$ and the results of clinician interviews. ${ }^{18}$ Any disagreements in coding were discussed until consensus among coders was reached. The entire research team met to discuss the codebook and its relevance to the data, and codebook revisions were made as needed. The two original coders then co-coded each transcript $(n=20)$.

Interview transcripts were iteratively coded and analyzed as described above. As analysis progressed, the coders performed open coding to inductively abstract more nuanced themes within the broader coding template, employing constant comparative analysis to regularly compare emergent codes and themes against the data, including an assessment of how preferences of participants interviewed pre- and post-discharge compared to one another. ${ }^{19}$ When necessary, transcripts were re-coded based on the revised codebook.

Throughout analysis, the coding team met weekly to evaluate emerging themes and resolve coding conflicts. ${ }^{23}$ Detailed descriptions of codes and associated text were provided to the entire research team to aid in coding validation and confirm shared interpretation and understanding. Percent agreement between coders was generally over $90 \%$ across all transcripts. Once it was determined that new insights were not emerging from the data, we deemed saturation had been reached and no new interviews were conducted.

\section{Results}

\section{Patient Characteristics}

Thirty-one patients and their family caregivers participated: one patient completed an individual interview post-discharge (November 2018); six patients and six caregivers attended focus groups (December 2018January 2019); five patients and two caregivers completed individual phone interviews (March-April 2019); and eleven patients completed individual interviews in the ED (May-June 2019). The response rate, when calculable, for focus group and phone interviews was $15 \%$ (ie, 133 patients and caregivers were approached). However, patients approached for the individual interviews conducted in the ED were not tracked. Participants' average age was 44 (SD 17); 51\% were male, the majority were White $(61 \%)$, approximately 
one third were Black (29\%), and 6\% were Hispanic/ Latino. Approximately one third had a high school diploma or less $(32 \%)$ and were employed full-time
(35\%). Combined, almost half had Medicaid (29\%) or Medicare (19\%) insurance. See Table 3 for complete participant demographics.

Table 3 Participant Demographics $(\mathrm{N}=3 \mathrm{I})$

\begin{tabular}{|c|c|c|}
\hline & $\mathbf{N}$ & SD $/ \%$ \\
\hline Age (Mean, SD) & 44 & 17 \\
\hline \multicolumn{3}{|l|}{ Gender } \\
\hline Male & 16 & 51 \\
\hline Female & 15 & 48 \\
\hline \multicolumn{3}{|l|}{ Race } \\
\hline White & 19 & 61 \\
\hline Black & 9 & 29 \\
\hline Other & 2 & 6 \\
\hline Missing & 1 & 3 \\
\hline \multicolumn{3}{|l|}{ Hispanic/Latino Ethnicity } \\
\hline Yes & 2 & 6 \\
\hline No & 26 & 84 \\
\hline Missing & 3 & 10 \\
\hline \multicolumn{3}{|l|}{ Education } \\
\hline$\leq$ High school & 10 & 32 \\
\hline Some college & 7 & 23 \\
\hline Associate & 1 & 3 \\
\hline$\geq$ College & 8 & 25 \\
\hline Missing & 5 & 16 \\
\hline \multicolumn{3}{|l|}{ Marital Status } \\
\hline Single & 12 & 39 \\
\hline Married & 7 & 23 \\
\hline Widowed & 4 & 13 \\
\hline Other & 5 & 16 \\
\hline Missing & 3 & 10 \\
\hline \multicolumn{3}{|l|}{ Employment Status } \\
\hline Full-time & II & 35 \\
\hline Part-time & 2 & 6 \\
\hline Not employed & 7 & 23 \\
\hline Disabled & 3 & 10 \\
\hline Other & 4 & 13 \\
\hline Missing & 4 & 13 \\
\hline \multicolumn{3}{|l|}{ Insurance type } \\
\hline Medicaid & 9 & 29 \\
\hline Medicare & 6 & 19 \\
\hline Employer-sponsored/Private & 8 & 25 \\
\hline Uninsured & 2 & 6 \\
\hline Other & 2 & 6 \\
\hline Missing & 4 & 13 \\
\hline
\end{tabular}




\section{Patient/Caregiver Themes}

Three common themes emerged regarding what syncope patients and caregivers expected when presenting to the ED with syncope including: (1) clarity regarding their diagnosis or cause of their syncope, (2) context surrounding their care plan and care teams' approach to diagnostic testing, and (3) to feel seen, heard and cared about by their health care team.

\section{Clarity Regarding Their Diagnosis or Cause of Syncope}

Syncope as a Symptom of an Underlying Disease/Disorder For approximately half of the patients in our study, syncope was recurrent and/or was a component of a complex medical history, with comorbidities such as heart disease, high blood pressure, stroke, etc. These factors likely heightened patients' and family caregivers' anxiety surrounding their syncopal episode and concerns that syncope could be related to a more serious issue. As one patient noted, "passing out, you know, is a serious thing. So, you never know what's going on." While many with recurrent syncope learned to live a normal life, a change in frequency or severity may have precipitated their recent visit to the $\mathrm{ED}$, and induced alarm and curiosity regarding its cause.

Over my life I just, like, maybe once a year, a couple times a year, I passed out. And I didn't really think anything about it. And then recently, I'd say like two months ago ... I started passing out a lot more. I would just get dizzy and-I don't really remember, like, until I guess about ten minutes after waking up. And I would be on the floor. He would just be shaking me or something like that.[Patient]

Consequently, patients sought clarity as to why they were having a syncopal event. As one patient noted, "If I come in here and it's something bad wrong [sic], then I would like you to find it. It's kind of your job".

\section{Emergency Department Means Action, Answers}

Going to the ED signaled to many that action would be taken and answers provided. As another patient noted, "Like, my thinking is why would they call it emergency department if they are going to sit down and watch?"

Patients Tended to Prefer Aggressive Approach to Testing Testing was often cited as the way patients and caregivers expected to arrive at the answer of why they fainted. The examples below come from patients describing their preference for an aggressive approach to testing (Also see Table 4).

I'd rather them find out what's wrong with me as soon as possible than wait. [Patient]

There is like a peace of mind knowing they're trying to figure out what's wrong. But when you are just waiting it's like, 'Okay, we might know what's going on. We might not.' It's like a 50-50 chance of what's going to happen. [Caregiver]

\section{Context Surrounding Their Care Plan or Diagnosis}

Patients and Family Caregivers Often Reported Insufficient Communication

Participants wanted more explanation and context surrounding their care plan or diagnoses, including why tests were or were not being done (Table 4).

I mean, they might've explained like each, you know, sample of blood, but not like in a way that me, as a patient, would really understand. You know, they might tell you that they check for this, but they're not telling anybody why [Patient]

The triage doctor only talks to you for about a good minute, two minutes. And they're already like 'I want this, this, and this ordered.' And I'm like wait, I didn't even tell you everything. [Patient]

Patient Preferences Regarding Testing Were Often Discussed in the Context of Communication

When directly asked, many patients expressed a preference for an aggressive approach to testing. However, regardless of whether patients seemed to prefer an aggressive or conservative approach, their opinions were usually discussed in the context of communication (Table 4). For example, some patients expressed that testing without sufficient communication provoked anxiety.

I feel like after maybe like the fourth test and stuff, do you really need any more tests? And because at that point, it's like is there something else wrong that we're not here for? Is there another problem to be thinking about? That just, like, brings this whole set of worries. [Patient]

Patient: [Aggressive testing] would just make me more nervous and question what's going on.

Interviewer: Would you expect them to kind of stop and explain every single test?

Patient: 
Table 4 Themes of Patient Expectations and Desires

\begin{tabular}{|c|c|c|}
\hline Theme & Sub-Theme & Quote \\
\hline \multirow{3}{*}{$\begin{array}{l}\text { Clarity surrounding their care } \\
\text { plan and diagnosis }\end{array}$} & Syncope as symptom of underlying problem & Passing out, you know, is a serious thing. So, you never know what's going on. \\
\hline & $\begin{array}{l}\text { Emergency department means action, } \\
\text { answers }\end{array}$ & $\begin{array}{l}\text { Like, my thinking is why would they call it emergency department if they are going } \\
\text { to sit down and watch? [Patient] }\end{array}$ \\
\hline & $\begin{array}{l}\text { Patients tended to prefer an aggressive } \\
\text { approach to testing }\end{array}$ & $\begin{array}{l}\text { If you leave here just thinking everything's gonna be fine and it might be. But six } \\
\text { months down the road, you might have some other issue that, you know, may not } \\
\text { have been caught, but [if you had done aggressive testing] you'd at least have that } \\
\text { better feeling of there's nothing else they could've done. [Patient] } \\
\text { - } \\
\text { Interviewer: Are you hoping that they run a lot of tests? Is that kind of your } \\
\text { expectation? } \\
\text { Patient: Yeah, cause I would really like to know why I started feeling so bad, and } \\
\text { especially why I pass out. Because that's really concerning. }\end{array}$ \\
\hline \multirow[t]{3}{*}{$\begin{array}{l}\text { Context surrounding their care } \\
\text { plan and approach to diagnostic } \\
\text { testing }\end{array}$} & $\begin{array}{l}\text { Patients and Caregivers often reported } \\
\text { insufficient communication }\end{array}$ & $\begin{array}{l}\text { I had } 3 \text { EKGs, which I never understood [why]. And I had an echocardiogram, and } \\
\text { I never understood why ... They just randomly came up like "Hey, we're going to } \\
\text { give you an echocardiogram." And I was like "Why?" "To check for something." } \\
\text { They did not even do it. [Patient] }\end{array}$ \\
\hline & $\begin{array}{l}\text { Patient preferences regarding testing were } \\
\text { often discussed in the context of } \\
\text { communication }\end{array}$ & $\begin{array}{l}\text { I could see how that ... like, in a way, [an aggressive approach to testing] would } \\
\text { make me happy, you know what I mean? Because I feel like they are really like, } \\
\text { concerned with what's going on and trying to figure it out... But then the other } \\
\text { side of me feels like maybe that [aggressive testing] could make me nervous, } \\
\text { because if there was like a bunch of doctors and stuff, like I might just feel like } \\
\text { something really serious is going on, because that's not usually how things, go, you } \\
\text { know? [ED Patient] }\end{array}$ \\
\hline & $\begin{array}{l}\text { Patient awareness and knowledge of } \\
\text { syncope varied }\end{array}$ & $\begin{array}{l}\text { The doctor himself never told me I had syncope. I never found out before they } \\
\text { moved me to the ICU on the floor. The nurse said something about it ... I asked } \\
\text { her if I could go smoke and she said "No, you have syncope ... I can't let you walk } \\
\text { around and stuff." And I said, "Well what's that?" [Patient] }\end{array}$ \\
\hline \multirow[t]{3}{*}{$\begin{array}{l}\text { Being seen, heard, and cared } \\
\text { about by their health care team }\end{array}$} & $\begin{array}{l}\text { Patients and caregivers wanted to feel seen, } \\
\text { heard, and cared about }\end{array}$ & $\begin{array}{l}\text { It's nice to know that somebody that you are seeing, a physician, or a care } \\
\text { specialist, or anything, really does not see you as a number. They see you as a } \\
\text { person. And want to take the time to find out what's wrong, or brush you off so } \\
\text { they can move on to their next patient. [Patient] }\end{array}$ \\
\hline & $\begin{array}{l}\text { Listening and attentive communication was } \\
\text { viewed as an indication of provider concern }\end{array}$ & $\begin{array}{l}\text { Patient: Actually, Hospital A is the only one that even gave us a remote feeling that } \\
\text { maybe I will know what's wrong now. } \\
\text { Interviewer: Right. Okay. And, what did they do at Hospital A that made you feel } \\
\text { that way? } \\
\text { Caregiver: They come out and say that they would know what-that they would } \\
\text { try their best to find out what the problem was. And they listened to what he was } \\
\text { saying to them. }\end{array}$ \\
\hline & $\begin{array}{l}\text { Testing was viewed as an indication of } \\
\text { providers' concern }\end{array}$ & $\begin{array}{l}\text { I could see how that ... like, in a way, [an aggressive approach to testing] would } \\
\text { make me happy, you know I mean? Because I feel like they are really like, } \\
\text { concerned with what's going on and trying to figure it out.[Patient] }\end{array}$ \\
\hline
\end{tabular}

Okay, yes. If we knew why they were doing every test maybe like ... instead of just like going in and out, "We're going to take for this, we are going to take for this."

Conversely, communication from the care team could allay potential fears associated with lack of testing. In some cases, patients noted that "if they tell me that's what I need ... that I don't need to get [additional testing] done, then that's fine." In other instances, when patients expressed a desire for aggressive testing, they indicated that if it was not provided, they would want more communication to supplement.

I would probably just wonder why they're not like asking me any serious questions or, you know, taking like-or doing - more of a better test on me. Like, explain to me what's going on or letting me know or ... trying to find out 
what's the reason for me fainting or passing out or whatever. I would want to know why they're not-they're not doing testing. [Patient]

\section{Patient Awareness of Syncope}

Patient knowledge of syncope and provider education surrounding syncope as a diagnosis varied greatly. While some participants expressed satisfaction with the explanations provided to them, most were unaware of the term "syncope" and reported that their provider did not use or did not fully explain this term. As one patient commented, "The doctor himself never told me I had syncope" (Table 4). Another patient noted that perhaps due to the recurrent nature of the patient's fainting, not as much information was required,

I felt pretty clear, but it was kind of ... it seemed kind of rushed. Which I understand. It's the ED ....I guess cause he had been there multiple times they kinda thought that, you know, he knew a lot about it.[Caregiver]

A caregiver also noted that although the word was used and explained, they were "so nervous and everything that I don't remember a lot of it."

Similar variety was reported in the educational materials provided to patients upon discharge from the ED or hospital. Some patients were satisfied with the information they received, "They did send a bunch of information home when I was released about that stuff. Paperwork, and things, what not to do, or, you know, when I feel one coming on." Conversely, other patients received no educational materials, contact information, nor discharge instructions upon discharge.

Interviewer: Did you receive any paperwork when you left the hospital? And not even like, nobody told you and what you need to do but did you receive any kind of like instruction, or discharge? [Interrupted]

Patient: No. No, no, no, no. Just saying, they made me sign a paper, I do not know, maybe the releasing paper or something?

Interviewer: So, did they send you with any like pamphlets or like information about passing out or anything like that?

Patient: No.

To Feel Seen, Heard, and Cared About

Aggressive Testing One Indication of Provider Care and Concern

Another theme among participants was the desire feel seen, heard, and cared about by their healthcare team. Many patients viewed an aggressive approach to testing as a way for the care team to show this concern (Table 4).

\section{Listening and Attentive Communication Showed Provider}

\section{Care and Concern}

Patients and caregivers also described listening and attentive communication as ways in which providers showed their care and concern. As one patient indicated, they felt comfortable at a hospital where the care staff focused on customer service, which they explained as, "They were more ... willing to explain more ... you know, more attentive of the patient being there." (Table 4) Another patient expressed the following.

Patient: It's nice to know that somebody that you are seeing, a physician, or a care specialist, or anything, really does not see you as a number. They see you as a person. And want to take the time to find out what's wrong, [not] brush you off so they can move on to their next patient.

Interviewer: Okay. So for you to feel like they see you as a person, what does-what does that type of care include?

Patient: Oh, listening, trying to help me figure out what's wrong, why am I [fainting].

\section{Comparison of Patients and Family Caregivers Interviewed Pre and Post Discharge}

Patients and family caregivers were recruited and interviewed pre- and post-discharge to allow for a comparison of how perspectives may vary at different time points; however, we found no clear distinctions in their reported preferences or experiences.

\section{Discussion}

Patients' needs and preferences play a critical role in care delivery, and thus, are crucial to address when implementing any new health care policy or practice, such as the 2017 Guidelines on Syncope. Our focus group and individual interviews with diverse patients and caregivers of patients admitted to the ED with syncope serve as one component of a larger mixed methods study aimed to identify the organizational, provider, and patient-level barriers to implementing the 2017 Syncope Guidelines and to develop an implementation intervention to address them.

Our prior focus group interviews conducted with diverse clinicians and stakeholders revealed multiple provider-perceived patient-level barriers, such as the need to 
satisfy patients' preferences for aggressive testing and communication challenges. The present study provides an important complement to those findings by soliciting perspectives directly from patients and their family caregivers. Importantly, our findings did align with the barriers reported by clinicians and healthcare stakeholders. Specifically, patients and caregivers in our study preferred an aggressive approach to testing. However, underlying this preference, we discovered other needs and desires that patients described regarding the evaluation and management of their syncope, including (1) clarity regarding their diagnosis or cause of their syncope, (2) context surrounding care plan and care teams' approach to diagnostic testing, and (3) to feel seen, heard and cared about by their health care team.

Patients desired clarity regarding the underlying cause of their syncopal episode, which led to requests of extensive diagnostic testing. The misalignment in this desire with guideline recommendations is that syncope is notoriously difficult to diagnose, even with testing. Syncope is relatively common, ${ }^{1}$ is also commonly benign, and can be a stand-alone diagnosis. However, it can also be a symptom of a more serious condition. ${ }^{24}$ Given syncope's multiple etiologies, and varying degrees of severity, its evaluation and management is challenging and often not value based. In fact, the tendency to over test, such as head CTs and echocardiograms, is common in the evaluation and management of syncope. In addition to avoiding the potential to miss a rare but deadly underlying condition, clinicians expressed concerns of malpractice litigation, loss of medical license, or poor patient experience associated with deviating from patient's preferences regarding extensive diagnostic testing. ${ }^{18}$ The result, however, is tremendous, unnecessary expense and burden for patients and the health care system. ${ }^{12,13}$

A concise medical history and physical evaluation are imperative for evaluating the patients' loss of consciousness. ${ }^{11}$ These procedures may render invasive and expensive testing unnecessary. Many participants in our study noted an absence of sufficient communication and engagement, despite their desires for it. Tests were ordered and administered without explanation, diagnoses were rendered and recorded in the medical record without being communicated to patients, and some patients did not feel they had the opportunity to share important contextual information surrounding their syncopal episode. When diagnosing and treating a condition as complex and contextually dependent as syncope, attentive, two-way communication is essential.

Focusing on active listening and two-way communication between clinicians and patients or caregivers is not only important diagnostically, but also factored into patients' desires to feel cared about by their health care providers. Quality communication is also fundamental to patient-centered care and for a positive patient experience. ${ }^{25-27}$ Participants in our study who discussed positive patient experiences often did so in the context of detailed and respectful communication.

One specific approach for patient-engaged communication that may be employed in the implementation of guideline recommendations is shared decision-making among patients and clinicians, a process that involves sharing information, eliciting patient values and preferences, and developing consensus for treatment plan. ${ }^{28}$ In fact, shared decision-making is recommended as a strategy to avoid unnecessary tests and treatments, ${ }^{29,30}$ increase patients' knowledge and reduce decisional conflict. $^{31}$ Such conversations can be challenging and emotion-laden, though, especially in circumstances when patient or family member desires do not align with best practice guidelines. However, fundamental elements of physician-patient communication can be used to guide clinicians' interactions with patients when discussing the treatment plan. Such elements include (1) allowing the patient to describe their symptoms; (2) clinician engagement in active listening and asking open-ended questions; (3) persuasive communication through presentation of facts and interpretation of their clinical significance to help correct misconceptions and persuade patients to make logical, informed decisions.

\section{Limitations}

This qualitative study collected in-depth information from both patients and their caregivers during multiple points in the care continuum, including pre and post discharge from the hospital or emergency department. However, we only sampled from one health system, which may not be generalizable to all syncope patients globally, or even nationally. In addition, our response rate, when calculable, was low at only $15 \%$, which may indicate sampling bias. We found that patients and family caregivers initially recruited to attend in-person focus groups post-discharge faced barriers to attending. There are only two Level 1 Trauma 
Centers in the state; patients may travel far distances to seek care and were unable to return for an in-person interview. While we attempted to overcome participation barriers by conducting phone-based interviews and interviews pre-discharge, the possibility remains that participants differ from syncope patients overall.

\section{Conclusion}

This study provides important contextual information about patient and family caregiver expectations and desires when confronted with various diagnostic and management procedures for a complex and often-mysterious condition: syncope. Patients and family caregivers in our study often expressed a preference for testing when presenting to the ED with syncope, but what they really wanted from healthcare providers was clarity, context, and care. Testing was often perceived as a means to achieve clarity and feeling cared about. Context around their plan of care, however, was crucially desired and too often lacking.

Taken together, evidence from our study supports that taking a multilevel, patient-engaged approach in the diagnosis and management of syncope may yield better adherence to the 2017 Guidelines on Syncope and result in fewer unnecessary and potentially burdensome tests.

For example, multimodal (eg, print, video) educational materials may help prepare patients waiting in the ED for the type of care and information to expect in their syncope evaluation and for the questions they may wish to ask their clinicians. In addition, clinicians can demonstrate their care for patients by engaging in active listening, obtaining complete patient histories, and engaging in shared decision-making with patients and family caregivers regarding the plan of care. Future research should test the effectiveness of such multifaceted implementation strategies in the implementation of the 2017 Guidelines on Syncope.

\section{Acknowledgments}

The authors wish to thank Hilary L. Surratt, PhD, for assistance with conducting interviews.

\section{Funding}

This project is funded by the National Heart, Lung, and Blood Institute through grant number 1U01HL143508-01 (J.L., M.V.W., S.S.S.)Role of the funding source: The funding source had no involvement in the study design; in the collection, analysis or interpretation of data; in the writing of the report; nor in the decision to submit the article for publication.

\section{Disclosure}

Dr Mark V Williams reports grants from National Heart, Lung and Blood Institute and the Center for Medicare and Medicaid Services (CMS) during the conduct of the study; received Salary from University of Kentucky, personal fees from OptumHealth Care Solutions, personal fees from Society of Hospital Medicine, from Northwestern University, outside the submitted work.

Dr Jing Li reports grants from NHLBI during the conduct of the study; served as NIH study section reviewer outside the submitted work. The authors declare no conflicts of interest.

\section{References}

1. Sun BC, Emond JA, Camargo CA Jr. Characteristics and admission patterns of patients presenting with syncope to U.S. emergency departments, 1992-2000. Acad Emerg Med. 2004;11(10):10291034. doi:10.1197/j.aem.2004.05.032

2. Costantino G, Sun BC, Barbic F, et al. Syncope clinical management in the emergency department: a consensus from the first international workshop on syncope risk stratification in the emergency department. Eur Heart J. 2016;37(19):1493-1498. doi:10.1093/eurheartj/ehv378

3. Rui P, Kang K. National hospital ambulatory medical care survey: 2014 emergency department summary tables; 2014. Available from: http://www.cdc.gov/nchs/data/ahcd/nhamcs_emergency/2014_ed_ web_tables.pdf. Accessed November 19, 2019.

4. Anderson JB, Czosek RJ, Knilans TK, Marino BS. The effect of paediatric syncope on health-related quality of life. Cardiol Young. 2012;22(5):583-588. doi:10.1017/S1047951112000133

5. Giada F, Silvestri I, Rossillo A, Nicotera PG, Manzillo GF, Raviele A. Psychiatric profile, quality of life and risk of syncopal recurrence in patients with tilt-induced vasovagal syncope. Europace. 2005;7 (5):465-471. doi:10.1016/j.eupc.2005.05.008

6. Linzer M, Pontinen M, Gold DT, Divine GW, Felder A, Brooks WB. Impairment of physical and psychosocial function in recurrent syncope. J Clin Epidemiol. 1991;44(10):1037-1043. doi:10.1016/08954356(91)90005-T

7. Rose MS, Koshman ML, Ritchie D, Sheldon R. The development and preliminary validation of a scale measuring the impact of syncope on quality of life. Europace. 2009;11(10):1369-1374. doi:10.1093/europace/eup 106

8. Santhouse J, Carrier C, Arya S, Fowler H, Duncan S. A comparison of self-reported quality of life between patients with epilepsy and neurocardiogenic syncope. Epilepsia. 2007;48(5):1019-1022. doi:10.1111/j.1528-1167.2006.00971.x

9. Faddis MN, Rich MW. Pacing interventions for falls and syncope in the elderly. Clin Geriatr Med. 2002;18(2):279-294. doi:10.1016/ S0749-0690(02)00010-1

10. Shen WK, Decker WW, Smars PA, et al. Syncope Evaluation in the Emergency Department Study (SEEDS): a multidisciplinary approach to syncope management. Circulation. 2004;110(24):36363645. doi:10.1161/01.CIR.0000149236.92822.07

11. Shen WK, Sheldon RS, Benditt DG, et al. 2017 ACC/AHA/HRS guideline for the evaluation and management of patients with syncope: a report of the American college of cardiology/American heart association task force on clinical practice guidelines and the heart rhythm society. $J$ Am Coll Cardiol. 2017;70(5):e39-e110. 
12. Probst MA, McConnell JK, Weiss RE, et al. Estimating the cost of care for emergency department syncope patients: comparison of three models. West J Emerg Med. 2017;18(2):253-257. doi:10.5811/ westjem.2016.10.31171

13. Tran DT, Sheldon RS, Kaul P, Sandhu RK. The current and future hospitalization cost burden of syncope in Canada. CJC Open. 2020;2 (4):222-228. doi:10.1016/j.cjco.2020.02.009

14. Smyth S, Gupta V, Williams M, et al. Identifying guideline-practice gaps to optimize evaluation and management for patients with syncope. Can J Cardiol. 2020;37(3):500-503. doi:10.1016/j. cjca.2020.05.022

15. McLintock B, Reid J, Capek E, Anderton L, Mitchell L. Unscheduled care bed days can be reduced with a syncope pathway and rapid access syncope clinic. Br J Cardiol. 2019;(26):133-136.

16. Elbaih AH, Elsakaya MS, Abdallah BS, Kamal HM. Risk stratification and the outcome in patients with syncope pre and post implementation of European society guidelines in emergency department in Ismailia Hospitals, Egypt. Int J Surg Med. 2020;6(1):1-10.

17. Damschroder LJ, Aron DC, Keith RE, Kirsh SR, Alexander JA, Lowery JC. Fostering implementation of health services research findings into practice: a consolidated framework for advancing implementation science. Implement Sci. 2009;4(1):50. doi:10.1186/17485908-4-50

18. Li J, Gupta V, Smyth SS, et al. Value-based syncope evaluation and management: perspectives of health care professionals on readiness, barriers and enablers. Am J Emerg Med. 2020;38(9):1867-1874. doi:10.1016/j.ajem.2020.05.029

19. Assarroudi A, Heshmati Nabavi F, Armat MR, Ebadi A, Vaismoradi M. Directed qualitative content analysis: the description and elaboration of its underpinning methods and data analysis process. $J$ Res Nurs. 2018;23(1):42-55. doi:10.1177/1744987117741667

20. Li J, Brock J, Jack B, et al. Project ACHIEVE - using implementation research to guide the evaluation of transitional care effectiveness [published correction appears in BMC Health Serv Res. 2016;16 (91):326]. BMC Health Serv Res. 2016;16:70. doi:10.1186/s12913016-1312-y
21. van der Weijden T, Légaré F, Boivin A, et al. How to integrate individual patient values and preferences in clinical practice guidelines? A research protocol. Implement Sci. 2010;5(1):10. doi:10.1186/ 1748-5908-5-10

22. Mitchell SE, Laurens V, Weigel GM, et al. Care transitions from patient and caregiver perspectives. Ann Fam Med. 2018;16(3):225231. doi:10.1370/afm.2222

23. Guest G, Bunce A, Johnson L. How many interviews are enough?: An experiment with data saturation and variability. Field Methods. 2006;18(1):59-82. doi:10.1177/1525822X05279903

24. Coleman DK, Long B, Koyfman A. Clinical mimics: an emergency medicine-focused review of syncope mimics. J Emerg Med. 2018;54 (1):81-89. doi:10.1016/j.jemermed.2017.09.012

25. Morgan S, Yoder LH, Concept A. Analysis of person-centered care. $J$ Holist Nurs. 2012;30(1):6-15. doi:10.1177/0898010111412189

26. Clever SL, Jin L, Levinson W, Meltzer DO. Does doctor-patient communication affect patient satisfaction with hospital care? Results of an analysis with a novel instrumental variable. Health Serv Res. 2008;43(5 Pt 1):1505-1519. doi:10.1111/j.14756773.2008.00849.x

27. Chandra S, Ward P, Mohammadnezhad M. Factors associated with patient satisfaction in outpatient Department of Suva Sub-Divisional Health Center, Fiji, 2018: a Mixed Method Study. Front Public Health. 2019;7:183. doi:10.3389/fpubh.2019.00183

28. Kon AA. The shared decision-making continuum. JAMA. 2010;304 (8):903-904. doi:10.1001/jama.2010.1208

29. Wolfson D, Santa J, Slass L. Engaging physicians and consumers in conversations about treatment overuse and waste: a short history of the choosing wisely campaign. Acad Med. 2014;89(7):990-995. doi:10.1097/ACM.0000000000000270

30. Born KB, Coulter A, Han A, et al. Engaging patients and the public in choosing wisely. BMJ Qual Saf. 2017;26(8):687-691. doi:10.1136/ bmjqs-2017-006595

31. Simmons M, Hetrick S, Jorm A. Shared decision-making: benefits, barriers and current opportunities for application. Australas Psychiatry. 2010;18(5):394-397.
Patient Preference and Adherence

\section{Publish your work in this journal}

Patient Preference and Adherence is an international, peer-reviewed, open access journal that focusing on the growing importance of patient preference and adherence throughout the therapeutic continuum. Patient satisfaction, acceptability, quality of life, compliance, persistence and their role in developing new therapeutic modalities and compounds to optimize clinical outcomes for existing disease states are major areas of interest for the journal. This journal has been accepted for indexing on PubMed Central. The manuscript management system is completely online and includes a very quick and fair peer-review system, which is all easy to use. Visit http:/ www.dovepress.com/testimonials.php to read real quotes from published authors. 